\title{
Review \\ Genetic factors in systemic sclerosis
}

Maureen D Mayes ${ }^{1}$ and Maria Trojanowska ${ }^{2}$

\begin{abstract}
1'Division of Rheumatology and Clinical Immunogenetics, University of Texas, Houston Health Science Center, Fannin, Houston, Texas 77030, USA
2Division of Rheumatology, Medical University of South Carolina, Jonathan Lucas Street, Charleston, South Carolina 29425, USA
\end{abstract}

Corresponding author: Maureen D Mayes, maureen.d.mayes@uth.tmc.edu

Published: 15 August 2007

This article is online at http://arthritis-research.com/content/9/S2/S5

(c) 2007 BioMed Central Ltd
Arthritis Research \& Therapy 2007, 9(Suppl 2):S5 (doi:10.1186/ar2189)

\section{Evidence for a genetic component to systemic sclerosis Familial studies}

A positive family history is the strongest risk factor thus far identified for SSc. A large US cohort-based study [1] found that although the absolute risk in individual family members was quite low $(<1 \%)$, in a small but significant proportion of families $(1.6 \%)$ more than one first-degree relative was affected, giving a familial relative risk of 13. A similar study in Australia [2] reported a recurrence rate in families of approximately $1 \%$, which is in relative agreement with the US estimate of $1.6 \%$.

In the current Scleroderma Family Registry of 693 index cases, in 16 families more than one person is affected; there are five sibling pairs and 11 parent-offspring pairs [3]. Unfortunately, the rarity of SSc precludes the generation of meaningful genetic information from family-based linkage studies, which have proved to be helpful in identifying genetic associations in other more common autoimmune diseases such as systemic lupus erythematosus and rheumatoid arthritis.

In general, studies of twins are considered the 'gold standard' for determining whether a disease is due to shared genetic predisposition or to shared environmental factors, whereby a higher concordance rate for a disease is expected in monozygotic than in dizygotic twins. In the only published SSc twin study to date [4] the concordance rate was low and no higher in monozygotic twins than in dizygotic twins. However, the incidence of antinuclear antibody positivity was higher in monozygotic twins than in dizygotic twins (90\% versus 40\%), suggesting at least a greater tendency toward disease in the former.

$\mathrm{ACA}=$ anticentromere; $\mathrm{ATA}=$ antitopoisomerase; $\mathrm{CTGF}=$ connective tissue growth factor; Fli1 = friend leukaemia integration $1 ; \mathrm{HLA}=$ human leucocyte antigen; PTPN22 = protein tyrosine phosphatase non-receptor type 22; SNP = single nucleotide polymorphism; SSc $=$ systemic sclerosis; $\mathrm{TGF}=$ transforming growth factor. 


\section{Genome-wide studies}

To date only one genome-wide association study in scleroderma has been reported. The Choctaw study [5] localized chromosome regions associated with susceptibility to SSc in a relatively isolated and homogeneous population of Choctaw Indians with a high prevalence of SSc. The affected individuals all had diffuse disease with pulmonary fibrosis, with over $80 \%$ being positive for Scl70. The study identified a total of 17 chromosome regions that were associated with SSc, including some that overlapped with regions identified in genome-wide studies of systemic lupus erythematosus and rheumatoid arthritis (Table 1; for reviews see the reports by Lee and Nath [6] and Etzel and coworkers [7]). One of the regions identified in this way is the human leucocyte antigen $(\mathrm{HLA})$ region on $6 \mathrm{p}$. The identity of other genes within these regions is currently unknown. It will be interesting to see respective data from a genome-wide scan in outbred nonChoctaw populations that is currently being undertaken in a study comparing approximately 5,000 SSc patients with 15,000 control individuals.

\section{What are the candidate genes in systemic sclerosis?}

The choice of which candidate genes to study can be daunting, considering the approximately 26,000 known genes. There are several approaches to this dilemma. The first is to choose genes in the regions that have been identified by the genome-wide scan [5]. The second is to study genes that have been identified in other autoimmune diseases and that appear to predispose to immune dysregulation. The third is to choose genes that play a key role in the aberrant pathways for a specific disease. As outlined below, all three approaches have been used in the study of scleroderma.

From a technical point of view, one of the methods used to identify candidate genes associated with a disease involves single nucleotide polymorphism (SNP) analysis. An SNP defines a genetic locus in which two or more alleles have gene frequencies greater than $1 \%$ in the population. SNP maps can help to identify multiple genes associated with complex diseases, which is difficult to achieve with conventional gene-hunting methods, because a single altered gene may make only a small contribution to the disease. The SNPs of greatest interest are nonsynonymous SNPs, namely those in which a single nucleotide change will yield a change in the encoded protein.

A number of interesting polymorphisms or gene variations have been associated with SSc (Table 2; for review, see the report by Assassi and Tan [8]), some of which are discussed in more detail below. However, one should bear in mind that SSc is a heterogeneous disease with multiple subtypes and that associations with particular polymorphisms may be based on the ethnic background of the populations studied. For example, although one report suggests an association of
Table 1

Gene regions significantly associated with systemic sclerosis in the Choctaw Indian population

\begin{tabular}{|c|c|c|}
\hline Region on chromosome & Marker & $P$ value \\
\hline $1 p 32-31$ & D1S255 & 0.0068 \\
\hline $1 \mathrm{p} 21.2^{\mathrm{a}}$ & D1S206 & $<0.0001$ \\
\hline $1 q 42.3^{a}$ & D1S2800 & 0.0012 \\
\hline $5 q 33.2^{a}$ & D5S410 & $<0.0001$ \\
\hline $6 p 22.3^{a}$ & D6S422 & 0.0368 \\
\hline $6 q 23-27^{a}$ & D6S264 & 0.0176 \\
\hline $7 p 12-11^{a}$ & D7S510 & 0.0017 \\
\hline $7 q 35$ & D7S661 & 0.005 \\
\hline $8 q 24.12$ & D8S514 & 0.0015 \\
\hline $14 q 21$ & D14S63 & 0.0173 \\
\hline $15 q 21.1^{a}$ & D15S978 & 0.0189 \\
\hline $19 p 13.2$ & D19S221 & 0.0016 \\
\hline $19 q 13.2^{a}$ & D19S220 & 0.0175 \\
\hline $20 q 12$ & D20S107 & 0.0095 \\
\hline $22 q 13.1$ & D22S423 & 0.0005 \\
\hline Xp11.4 & DXS1068 & 0.0026 \\
\hline$X q 21-23$ & DXS8055 & 0.0082 \\
\hline
\end{tabular}

aRegions that are common to systemic lupus erythematosus and/or rheumatoid arthritis.

endothelial nitric oxide synthase with SSc [9], other groups found no such association [10,11]. In general, disease associations with particular SNP polymorphisms are usually not considered 'true' until they have been confirmed in an independent cohort.

Similarly, there are conflicting reports on the association of $S P A R C$ (secreted protein, acidic and rich in cysteine) polymorphisms with SSc [12,13]. This lack of confirmation may be due to the fact that Zhou and coworkers [12] studied the Choctaw Indians, a relatively inbred group with homogeneous disease expression, whereas Lagan and coworkers [13] studied a more heterogeneous scleroderma cohort. This association must be confirmed (or rejected) in a scleroderma cohort with diffuse disease and antitopoisomerase antibodies (ATA). Until then, this association must be considered unverified.

\section{PTPN22 R620W polymorphism}

The PTPN22 gene encodes the lymphoid-specific protein tyrosine phosphatase nonreceptor type 22, which resides on on the short arm of chromosome 1 (area 1p13). The presence of the minor allele R620W results in the substitution of tryptophan for arginine at the binding site of the protein, which disrupts its ability to bind to protein kinase, 
Table 2

\begin{tabular}{lccl}
\multicolumn{4}{l}{ Candidate gene polymorphisms associated with systemic sclerosis } \\
\hline Encoded protein (gene location) & Patient $(n)$ & Control $(n)$ & Association \\
\hline TNF promoter (6p21.3) & 214 & 354 & -1031 C allele and -863 A allele strongly associated with ACA-positive SSc [37] \\
TNF- $\alpha$ (6p21.3) & 114 & 170 & -238 and +489 A alleles are weakly associated with SSc [38] \\
TNF-RIl (chromosome 9) & 114 & 170 & TNF-RIl -196 polymorphism is not associated with SSc [38] \\
MCP-1 promoter (17q11.2) & 18 & 139 & -2518 G/G phenotype is associated with SSc [39] \\
IL-1A (2q14) & 60 & 70 & IL-1A gene polymorphism is associated with SSc [40] \\
IL-1A (2q14) & 46 & 150 & IL-1A -889T allele is associated with SSc [41] \\
eNOS (7q36) & 73 & 112 & eNOS is associated with SSc [9] \\
eNOS (7q36) & 77 & 49 & eNOS G894T is not associated with SSc [10] \\
eNOS (7q36) & 164 & 184 & eNOS G894T is not associated with SSc [11] \\
SPARC (5q31.3-32) & 20 & 75 & SPARC polymorphisms are associated with SSc [12] \\
SPARC (5q31.3-32) & 121 & 200 & SPARC polymorphisms are not associated with SSc [13]
\end{tabular}

ACA, anticentromere antibody; eNOS, endothelial nitric oxide synthase; IL, interleukin; MCP, monocyte chemoattractant protein; SPARC, secreted protein, acidic and rich in cysteine; TNF, tumour necrosis factor; TNF-RII, TNF receptor II.

thereby preventing its normal metabolism [14]. This increases PTPN22 protein activity and, as a result, the threshold required for T-cell receptor signalling in the thymus. It is speculated that the mutation might induce autoimmunity by preventing the deletion of autoreactive $\mathrm{T}$ cells, resulting in insufficient activity in regulatory $T$ cells.

A positive association of the PTPN22 R620W polymorphism has been identified for patients with SSc, and more specifically for the subgroup of SSc patients who are ATA positive and those who are anticentromere antibody (ACA) positive [15]. This study evaluated 1,120 SSc patients and 816 control individuals. The odds ratio in the ATA-positive patients compared with control individuals was 2.36 (95\% confidence interval 1.5 to 3.6 ), and the odds ratio in the ACA-positive patients was 1.71 (95\% confidence interval 1.1 to 2.6). Two other studies, namely those by Balada [16] and Wipff [17] and colleagues, failed to find an association with this polymorphism, but the number of cases and controls in these studies was quite small (the Balada study included only 54 cases and 55 controls, whereas the Wipff study included 121 cases and 103 controls). Therefore, the negative findings in these latter two studies are probably due to their being underpowered to detect an association with an odds ratio of this magnitude.

Positive associations have been found for a number of other immune diseases, including rheumatoid arthritis and systemic lupus erythematosus (Table 3). The PTPN22 R620W polymorphism is not uniformly associated with autoimmune diseases, however. There are some autoimmune diseases for which no association with this particular polymorphism has been found (Table 3; for review, see the report by Gregersen and Batliwalla [18]).
Table 3

PTPN22 R620W polymorphism and links with immune diseases

\begin{tabular}{ll}
\hline Association identified & No association \\
\hline $\begin{array}{l}\text { Scleroderma: ATA positive } \\
\text { and ACA positive }\end{array}$ & Multiple sclerosis \\
RA and JRA & Coeliac disease \\
SLE & Primary sclerosis cholangitis \\
Type I diabetes mellitus & Crohn's disease \\
Grave's and Addison's & Psoriasis \\
Psoriatic arthritis & Ankylosing spondylitis \\
Wegener's granulomatosis & Primary Sjögren's syndrome \\
\hline
\end{tabular}

This area of research is reviewed by Gregersen and Batliwalla [18]. ACA, anticentromere antibody; ATA, antitopoisomerase antibody; JRA, juvenile rheumatoid arthritis; RA, rheumatoid arthritis; SLE, systemic lupus erythematosus.

\section{AIF1 polymorphism}

This polymorphism is located in the class III region, close to the tumour necrosis factor gene cluster. The encoded protein, allograft inflammatory factor 1, is detected in vasculopathic vessels, for example after balloon angioplasty. It is inducible in vascular smooth muscle cell cultures by proinflammatory cytokines and promotes activation and proliferation of vascular smooth muscles cells $[19,20]$. The gene is upregulated in skin biopsies and peripheral blood cells of scleroderma patients as compared with those of matched control individuals in gene expression studies [21-23]. 
A nonsynonymous SNP (AIF-1 gene SNP rs2269475) that results in a tryptophan to arginine amino acid substitution is found at a higher frequency in patients with SSc than in control individuals [24]. To date, it is not clear whether the amino acid substitution affects the function of the protein, and therefore the functional significance of this change is unknown.

\section{HLA gene region polymorphisms}

The HLA gene region is an extreme example of genetic polymorphism. We recently completed a study of 1,100 patients in which we looked at several HLA class II associations and were able to verify the findings of multiple previous studies. Grouped by race or ethnicity, none of the HLA associations were consistent in all groups. However, grouped according to autoantibody status [25], for example ATA, ACA, or RNA polymerase, the findings were consistent between different ethnic groups. It therefore seems likely that the gene associations may in fact be associated with subphenotypes, particularly as defined by autoantibody expression, rather than with SSc as a single disease entity.

An important area of future research will be to determine whether these sub-phenotypes also predict response to therapy.

\section{Gene profiling in systemic sclerosis}

In general, the molecular and cellular mechanisms that maintain proper collagen homeostasis in healthy human skin and are responsible for the dysregulated collagen synthesis in SSc remain unknown. In an attempt to identify the genes that are involved in this process, gene profiling studies have been undertaken; gene profiling is a useful technique for comparing gene expression between normal and diseased cells. Gene profiling of SSc skin biopsies revealed robust signatures of disease, identifying changes in expression of about 1,800 genes that distinguish normal skin from SSc skin at a significant level [22]. Alterations in transforming growth factor- $\beta$ and Wnt pathways, extracellular matrix proteins and the CCN family were prominent. However, the changes identified are not fully reflected in the profiles of explanted fibroblasts. This observation suggests that studies conducted in biopsy material are likely to prove more useful in the complex disease pattern of SSc than cultured fibroblasts.

In addition to gene polymorphisms, epigenetic mechanisms such as the degree of methylation or copy number variations can change gene expression and result in a pathological state. Such may be the case with Fli1.

\section{The role of Fli1 in the pathogenesis of systemic sclerosis}

\section{Fli1 expression in fibroblasts}

Fli1 belongs to the family of Ets transcription factors that were recently shown to be dysregulated in many immune diseases [26]. Until relatively recently, Fli1 was considered to
Figure 1

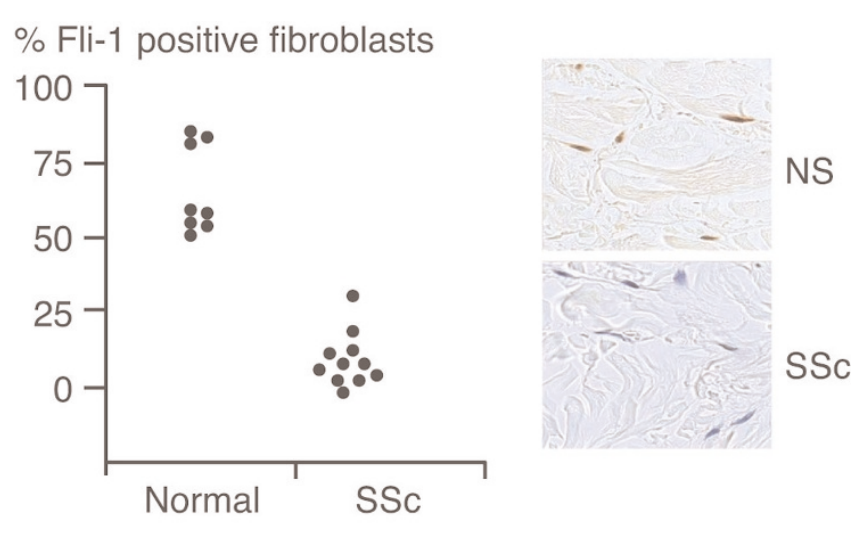

$66 \pm 14 \%$ vs $8 \pm 8 \%, P<0.001$

Fli1 is absent in the majority of fibroblasts in SSc skin. Fli1, friend leukaemia integration 1; NS, normal skin; SSc, systemic sclerosis. Reprinted from Kubo et al. Am J Pathol 2003, 163:571-581 with permission from the American Society for Investigative Pathology [27].

be merely an immune cell transcription factor and was not known to be expressed in fibroblasts. However, the finding that Fli1 expression levels in cultured human and mouse fibroblasts are inversely correlated with collagen type I expression levels suggested that it may be a repressor of collagen genes. Evidence for a role for Fli1 in regulating collagen synthesis in cultured dermal fibroblasts and in human skin in vivo was recently provided. Immunostaining for Fli1 in normal skin biopsies revealed that although $70 \%$ of fibroblasts were positive for Fli1, there was little evidence of Fli1-positive fibroblasts in SSc skin biopsies (Figure 1). The absence of Fli1 correlated with enhanced collagen synthesis in SSc skin. Fli1 was shown to be required to maintain the repressed state of the fibrillar collagen genes [27,28]. A recent study suggested that epigenetic mechanisms may be responsible for downregulation of Fli1 in SSc skin in vivo [29].

In order to investigate how Fli1 maintains this repressed state, the effects of Fli1 expression on regulation of genes that were differentially expressed in SSc biopsies but not in normal skin were examined [30]. This study showed that Fli1 directly regulates the expression of connective tissue growth factor (CTGF), also known as CCN2. Downregulation of Fli1 upregulated expression of CTGF mRNA, which mimics to some extent the profibrogenic effects of transforming growth factor (TGF)- $\beta$. This is an important finding, because there is little detectable TGF- $\beta$ during fibrosis in SSc, other than during the very early stage.

In addition to upregulation of CTGF, blocking Fli1 also affected the expression of some other genes in the biopsy. The expression of collagen mRNA was increased, as well as that of PLOD2, which is known to be very important for 
collagen cross-linking [31]. As well as upregulating certain genes in SSc biopsies, blocking Fli1 resulted in the downregulation of others; one of these was the gene encoding decorin, which also probably contributes to fibrillar genesis.

Although the results from the in vitro studies on human fibroblasts strongly suggested that reduced expression of Fli1 had a profibrotic effect, this must also be demonstrated in vivo. The Fli $1^{\%}$ genotype is lethal, with mice dying from cranial or spinal haemorrhages at day 11.5 [32]. Therefore, a heterozygous model was initially used, with a $50 \%$ reduction in Fli1 levels, which is viable and exhibits absolutely no phenotype. Levels of interstitial collagen mRNA were only slightly elevated in Fli1 ${ }^{+/}$mice; however, it could be demonstrated that they produced elevated levels of acetic acid extractable collagen and of type I collagen. Importantly, an increase in fibril diameter by electron microscopy could also be demonstrated, which is also found in SSc patients. Homozygous Fli1 mice carrying a Fli1 gene that lacks a carboxyl-terminal domain (Fli1 ${ }^{\Delta C T A}$ ) were recently generated. Fibroblasts from these mice maintain the activated phenotype when cultured; these should prove useful in further elucidating the role played by Fli1 in pathogenesis.

In summary, the recent observations provide valuable support for the role of dysregulation of Fli1 in contributing to the development of fibrosis in SSc. What is not yet clear is what factors (genetic, environmental, or immunological) are responsible for downregulating Fli1 in SSc.

\section{Fli1 expression in the vascular compartment and its potential role in vessel degradation}

As well as being expressed in healthy fibroblasts, Fli1 is highly expressed in endothelial cells, and probably in pericytes and other cells around blood vessels. As well as being downregulated in affected SSc skin, Fli1 is also downregulated in areas of uninvolved skin from SSc patients (Figure 2).

Staining of microvessels in the homozygous Fli1 ${ }^{\Delta \mathrm{CTA}}$ mice compared with Fli ${ }^{+/+}$mice revealed downregulation of a number of proteins that are known to be involved in endothelial-mural interactions. These included smooth muscle actin, desmin and platelet-derived growth factor receptor $\beta$. Similar features were observed in human biopsies. In healthy skin smooth muscle actin positive cells around the vessels may be clearly observed near the epidermis and in deep dermis. In SSc uninvolved skin we see malformed vessels that are still partially covered by pericytes, and in SSc involved skin we see very few vessels near the epidermis and none in deep dermis (Figure 3).

A possible explanation for why vessels degenerate in SSc relates to angiogenesis, because angiogenesis involves a number of sequential steps, including the following: detach-

\section{Figure 2}

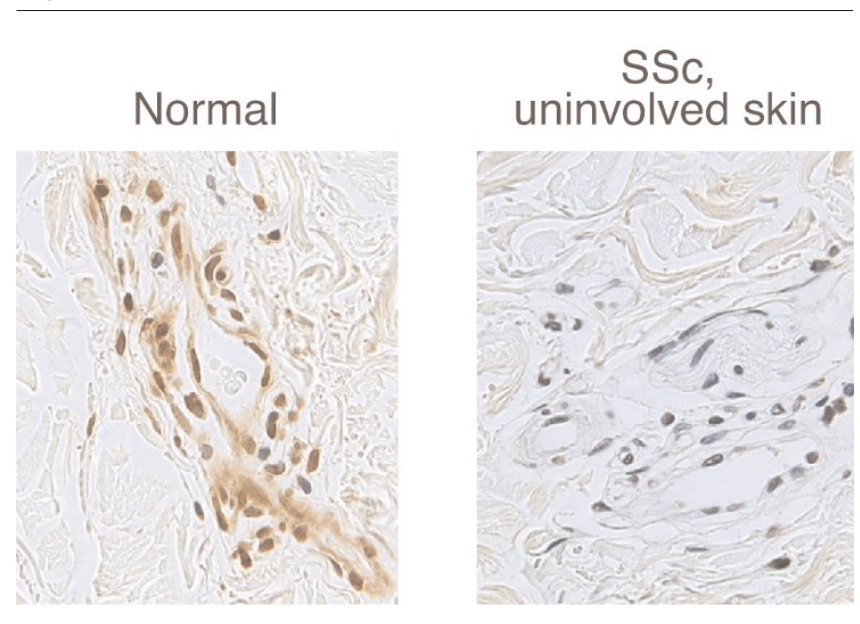

Fli1 is downregulated in microvessels in SSc skin. SSc, systemic sclerosis. Reprinted from Kubo et al. Am J Patho/ 2003, 163:571-581 with permission from the American Society for Investigative Pathology [27].

\section{Figure 3}

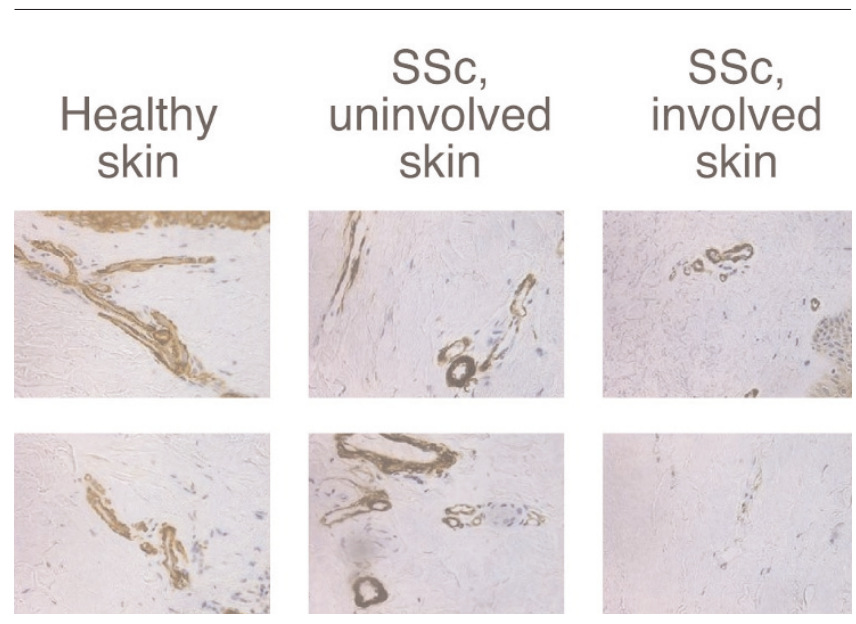

Comparison of $\alpha$-SMA staining in healthy and SSc skin. SMA, smooth muscle actin; SSc, systemic sclerosis.

ment of pre-existing pericytes or vascular destabilization; extracellular matrix degradation by endothelial proteases; migration and proliferation of endothelial cells; tube formation by endothelial cells; and, finally, reattachment of pericytes for vascular stabilization [33,34]. In SSc skin it appears that the vessels undergo proliferation when angiogenesis begins, but they experience problems with reattachment of pericytes, vessel maturation and stabilization. Using a three-dimensional co-culture model to study the effect of Fli1 on dermal microvascular endothelial cells covered by human collagen and fibroblasts, we found that reducing Fli1 levels had a proangiogenic effect, with increased tube formation, cell migration and apoptosis in the collagen matrix [35]. These 
findings suggest that in SSc there may be a problem with vessel stability or maturation, or some kind of interaction between endothelial cells and pericytes. Work in cancer has shown that if pericytes are not present, then such vessels do not survive [36].

\section{Conclusion}

Understanding of the genetic factors involved in SSc has increased considerably in recent years. There is doubtless a role for genes, in terms of either susceptibility or influencing the phenotypic expression of the disease. On a broad level, genetic studies are proving valuable in identifying genomic regions with possible associations with SSc and, at the same time, emphasizing the complexity of this disease, which appears to represent a collection of phenotypes rather than a single disease entity.

It is likely, based on results from PTPN22 studies and from HLA studies, that there will be 'general' autoimmune disease genes (such as PTPN22) and scleroderma specific genes (like the HLA region associations). This area is undergoing rapid change and is expected to provide new insights into pathogenesis as well as therapeutic approaches.

The findings of gene profiling investigations are beginning to provide us with possible mechanisms to explain, at least in part, some of the complex pathogenesis that is involved in SSc, with downregulation of Fli1 expression appearing to play a central role. However, there remains much to learn, including identification of the trigger(s) that result in the development of this complex disease.

\section{Competing interests}

The authors declare that they have no competing interests.

\section{Acknowledgements}

The authors would like to acknowledge medical writing support funded by an educational grant from Actelion Pharmaceuticals Ltd.

This article is part of Arthritis Research \& Therapy Volume 9 Supplement 2: Advances in systemic sclerosis and related fibrotic and vascular conditions, and is based on presentations made at a symposium entitled Advances in systemic sclerosis and connective tissue disease, sponsored by Actelion Pharmaceuticals Ltd, held in Athens, Greece in April 2006. The full contents of the supplement are available online at http://arthritis-research.com/ supplements/9/S2. This supplement has been supported by an educational grant from Actelion Pharmaceuticals Ltd.

\section{References}

1. Arnett FC, Cho M, Chatterjee S, Aguilar MB, Reveille JD, Mayes $\mathrm{MD}$ : Familial occurrence frequencies and relative risks for systemic sclerosis (scleroderma) in three United States cohorts. Arthritis Rheum 2001, 44:1359-1362.

2. Englert H, Small-McMahon J, Chambers P, O'Connor H, Davis K, Manolios N, White R, Dracos G, Brooks P: Familial risk estimation in systemic sclerosis. Aust N Z J Med 1999, 29:36-41.

3. Assassi S, Arnett FC, Reveille JD, Gourh P, Mayes MD: Clinical, immunological, and genetic features of familial systemic sclerosis. Arthritis Rheum 2007:in press.

4. Feghali-Bostwick C, Medsger TA, Wright TM: Analysis of systemic sclerosis in twins reveals low concordance for disease and high concordance for the presence of antinuclear antibodies. Arthritis Rheum 2003, 48:1956-1963.
5. Zhou X, Tan FK, Wang N, Xiong M, Maghidman S, Reveille JD, Milewicz DM, Chakraborty R, Arnett FC: Genome-wide association study for regions of systemic sclerosis susceptibility in a Choctaw Indian population with high disease prevalence. Arthritis Rheum 2003, 48:2585-2592.

6. Lee YH, Nath SK: Systemic lupus erythematosus susceptibility loci defined by genome scan meta-analysis. Hum Genet 2005, 118:434-443.

7. Etzel CJ, Chen WV, Shepard N, Jawaheer D, Cornelis F, Seldin MF, Gregersen PK, Amos Cl, for the North American Rheumatoid Arthritis Consortium: Genome-wide meta-analysis for rheumatoid arthritis. Hum Genet 2006, 119:634-641.

8. Assassi S, Tan FK: Genetics of scleroderma: update on single nucleotide polymorphism analysis and microarrays. Curr Opin Rheumatol 2005, 17:761-767.

9. Fatini C, Gensini F, Sticchi E, Battaglini B, Angotti C, Conforti ML, Generini S, Pignone A, Abbate R, Matucci-Cerinic M: High prevalence of polymorphisms of angiotensin-converting enzyme (I/D) and endothelial nitric oxide synthase (Glu298Asp) in patients with systemic sclerosis. Am J Med 2002, 112:540544.

10. Allanore $Y$, Borderie $D$, Lemarechal $H$, Ekindjian $O G$, Kahan $A$ : Lack of association of eNOS (G894T) and p22phox NADPH oxidase subunit (C242T) polymorphisms with systemic sclerosis in a cohort of French Caucasian patients. Clin Chim Acta 2004, 350:51-55.

11. Assassi S, Mayes MD, McNearney T, Fischbach M, Reveille JD, Arnett FC, Tan FK: Polymorphisms of endothelial nitric oxide synthase and angiotensin-converting enzyme in systemic sclerosis. Am J Med 2005, 118:907-911.

12. Zhou X, Tan FK, Reveille JD, Wallis D, Milewicz DM, Ahn C, Wang A, Arnett FC: Association of novel polymorphisms with the expression of SPARC in normal fibroblasts and with susceptibility to scleroderma. Arthritis Rheum 2002, 46:2990-2999.

13. Lagan AL, Pantelidis $P$, Renzoni EA, Fonseca C, Beirne P, Taegtmeyer $\mathrm{AB}$, Denton $\mathrm{CP}$, Black CM, Wells AU, du Bois RM, et al:: Single-nucleotide polymorphisms in the SPARC gene are not associated with susceptibility to scleroderma. Rheumatology (Oxford) 2005, 44:197-201.

14. Gregersen PK: Pathways to gene identification in rheumatoid arthritis: PTPN22 and beyond. Immunol Rev 2005, 204:74-86.

15. Gourh P, Tan FK, Assassi S, Ahn CW, McNearney TA, Fischbach M, Arnett FC, Mayes MD: Association of the PTPN 22 R620 polymorphism with anti-topoisomerase 1- and anticentromere antibody-positive systemic sclerosis. Arthritis Rheum 2006, 54:3945-3953.

16. Balada E, Simeon-Aznar CP, Serrano-Acedo S, Martinez-Lostao L, Selva-Callaghan A, Fonollosa-Pla V, Vilardell-Tarres M: Lack of association of the PTPN22 gene polymorphism R620W with systemic sclerosis. Clin Exp Rheum 2006, 24:321-324.

17. Wipff J, Allanore Y, Kahan A, Meyer O, Mouthon L, Guillevin L, Pierlot C, Glikmans E, Bardin T, Boileau C, et al:: Lack of association between the protein tyrosine phosphatase non-receptor 22 (PTPN22)*620W allele and systemic sclerosis in the French Caucasian population. Ann Rheum Dis 2006, 65:12301232.

18. Gregersen PK, Batliwalla F: PTPN22 and rheumatoid arthritis: gratifying replication. Arthritis Rheum 2005, 52:1952-1955.

19. Autieri MV, Kelemen S, Thomas BA, Feller ED, Goldman BI, Eisen $\mathrm{HJ}$ : Allograft inflammatory factor-1 expression correlates with cardiac rejection and development of cardiac allograft vasculopathy. Circulation 2002, 106:2218-2223.

20. Autieri MV, Carbone CM: Overexpression of allograft inflammatory factor-1 promotes proliferation of vascular smooth muscle cells by cell cycle deregulation. Arterioscler Thromb Vasc Biol 2001, 21:1421-1426.

21. Del Galdo F, Maul GG, Jimenez SA, Artlett CM: Expression of allograft inflammatory factor 1 in tissues from patients with systemic sclerosis and in vitro differential expression of its isoforms in response to transforming growth factor beta. Arthritis Rheum 2006, 54:2616-2625.

22. Gardner H, Shearstone JR, Bandaru R, Crowell T, Lynes M, Trojanowska M, Pannu J, Smith E, Jablonska S, Blaszczyk M, et al.: Gene profiling of scleroderma skin reveals robust signatures of disease that are imperfectly reflected in the transcript profiles of explanted fibroblasts. Arthritis Rheum 2006, 54:19611973. 
23. Tan FK, Zhou X, Marcum C, Gourh P, Mayes MD, Jin L, Arnett FC: Signatures of differentially regulated interferon gene expression and vasculotrophism in the peripheral blood cells of systemic sclerosis patients. Rheumatology (Oxford) 2006, 45:694-702.

24. Alkassab F, Gourh P, Tan FK, McNearney T, Fischbach M, Arnett FC, Mayes MD: Allograft inflammatory factor 1 (AIF1) single nucleotide polymorphism (SNP) is associated with anticentromere antibody seropositive systemic sclerosis. Rheumato/ogy (Oxford) 2007:in press.

25. Mayes MD, Ahn C, Arnett FC, Reveille JD: HLA class II associations in systemic sclerosis (SSc) from the Scleroderma Family Registry and DNA Repository. Arthritis Rheum 2005, Suppl:S582.

26. Zhang L, Eddy A, Teng YT, Fritzler M, Kluppel M, Melet F, Bernstein $A$ : An immunological renal disease in transgenic mice that overexpress Fli-1, a member of the ets family of transcription factor genes. Mol Cell Biol 1995, 15:6961-6970.

27. Kubo M, Czuwara-Ladykowska J, Moussa O, Markiewicz M, Smith E, Silver RM, Jablonska S, Blaszczyk M, Watson DK, Trojanowska $\mathrm{M}$ : Persistent down-regulation of Fli1, a suppressor of collagen transcription, in fibrotic scleroderma skin. Am J Pathol 2003, 163:571-581.

28. Czuwara-Ladykowska J, Shirasaki F, Jackers P, Watson DK, Trojanowska M: Fli-1 inhibits collagen type I production in dermal fibroblasts via an Sp1-dependent pathway. J Biol Chem 2001, 276:20839-20848.

29. Wang Y, Fan PS, Kahaleh B: Association between enhanced type 1 collagen expression and epigenetic repression of the FLI1 gene in scleroderma fibroblasts. Arthritis Rheum 2006, 54:3945-3953

30. Nakerakanti SS, Kapanadze B, Yamasaki M, Markiewicz M, Trojanowska M: Fli1 and Ets1 have distinct roles in connective tissue growth factor/CCN2 gene regulation and induction of the profibrotic gene program. J Biol Chem 2006, 281:2525925269.

31. van der Slot AJ, Zuurmond AM, Bardoel AF, Wijmenga C, Pruijs $\mathrm{HE}$, Sillence DO, Brinckmann J, Abraham DJ, Black CM, Verzijl N, et al.: Identification of PLOD23 as telopeptide lysyl hydroxylase, an important enzyme in fibrosis. $J$ Biol Chem 2003, 278: 40967-40972.

32. Spyropoulos DD, Pharr PN, Lavenburg KR, Jackers P, Papas TS, Ogawa M, Watson DK: Hemorrhage, impaired hematopoiesis, and lethality in mouse embryos carrying a targeted disruption of the Fli1 transcription factor. Mol Cell Biol 2000, 20:56435652 .

33. Hanahan D: Signaling vascular morphogenesis and maintenance. Science 1997, 277:48-50.

34. Koch AE, Distler O: Vasculopathy and disordered angiogenesis in selected rheumatic diseases: rheumatoid arthritis and systemic sclerosis. Arthritis Res Ther 2007, 9(Suppl 2):S3.

35. Yamasaki M, Kapanadze B, Markiewicz M, Trojanowska M: Downregulation Of fli1 in human microvascular endothelial cells promotes cell survival and leads to cord formation in 3D collagen gels. The Proceedings of Miami Nature Biotechnology Winter Symposium. The cell cycle, chromosomes and cancer. Miami, Florida, USA. Vol. 17, 2006 [http://www.med.miami.edu/ mnbws/documents/06Yamasaki.pdf]

36. Benjamin LE, Golijanin D, Itin A, Pode D, Keshet E: Selective ablation of immature blood vessels in established human tumors follows vascular endothelial growth factor withdrawal. $J$ Clin Invest 1999, 103:159-165.

37. Sato H, Lagan A, Alexopoulou C, Vassilakis DA, Ahmad T, Pantelidis $\mathrm{P}$, Veeraraghavan $\mathrm{S}$, Renzoni E, Denton $\mathrm{C}$, Black $\mathrm{C}$, et al.: The TNF863A allele strongly associates with anticentromere antibody positivity in scleroderma. Arthritis Rheum 2004, 50: 558-564.

38. Tolusso B, Fabris M, Caporali R, Cuomo G, Isola M, Soldano F, Montecucco C, Valentini G, Ferraccioli G: -238 and +489 TNF alpha along with TNFRII gene polymorphisms associate with diffuse phenotype in patients with systemic sclerosis. Immunol Lett 2005, 96:103-108.

39. Karrer S, Bosserhoff AK, Weiderer P, Distler O, Landthaler M, Szeimies RM, Muller-Ladner U, Scholmerich J, Hellerbrand C: The -2518 promotor polymorphism in the MCP-1 gene is associated with systemic sclerosis. J Invest Dermatol 2005, 124:9298.
40. Kawaguchi $Y$, Tochimoto A, Ichikawa $N$, Harigai $M$, Hara $M$, Kotake S, Kitamura Y, Kamatani N: Association of IL1A gene polymorphism with susceptibility to and severity of systemic sclerosis in the Japanese population. Arthritis Rheum 2003, 48:186-192.

41. Hutyrova B, Lukac J, Bosak V, Buc M, du Bois R, Petrek M: Interleukin 1alpha single-nucleotide polymorphism associated with systemic sclerosis. J Rheumato/ 2004, 31:81-84. 